\title{
Preliminary laboratory tests of a new fibre optic high temperature measurement device
}

\author{
EwA LISIECKA
}

Central Mining Institute, Department of Technical Acoustic and Laser Technique, Plac Gwarków 1, 40-166 Katowice, Poland; elisiecka@gig.eu

\begin{abstract}
This article presents the laboratory verification of the author's algorithm for temperature determination. The conducted tests confirm the ability to eliminate the measurement condition impact (emissivity of the radiation source, attenuation of the atmosphere) on non-contact thermometric measurement results. What is more, this method allows measurement for wavelength shorter than $1 \mu \mathrm{m}$ to be carried out. The second stage of the work involved transmission tests of the fibre optic probe. The use of three quartz rods ensured that thermal radiation from each direction in a perpendicular plane to the probe head is collected and transmitted. The combination of the new temperature determination method and new constructed measurement instrument will allow the area of application of a non-contact thermometric device to be extended.
\end{abstract}

Keywords: non-contact thermometer, high temperature measurements, fibre optic probe.

\section{Introduction}

Non-contact thermometric devices have a wide range of applications in the military, industry, research and medicine. Devices of this kind are divided into two groups: pyrometers allowing the temperature of the objects to be measured and thermal cameras which additionally enable imaging of spatial temperature distribution.

The common non-contact temperature measurements are based on blackbody radiation laws, such as Stefan-Boltzmann law, Plank's law and Wien's displacement law. Thermal radiation from the object's surface where the temperature is above absolute zero is emitted in all directions into the hemisphere above the surface. The blackbody is an ideal object and does not exist in reality. According to the emission ability of the objects, three groups of bodies could be distinguished: black, grey and real [1].

The real objects partially absorb, partially reflect and partially transmit electromagnetic radiation including thermal radiation. The ability to emit the thermal radiation from the object is described by a parameter called emissivity.

This parameter is difficult to determine and depends on various variables such as temperature, wavelength, chemical composition and surface condition [ $1 \underline{-} \underline{3}]$. In Fig. 1 the variation of the emissivity caused by the wavelength is presented. 


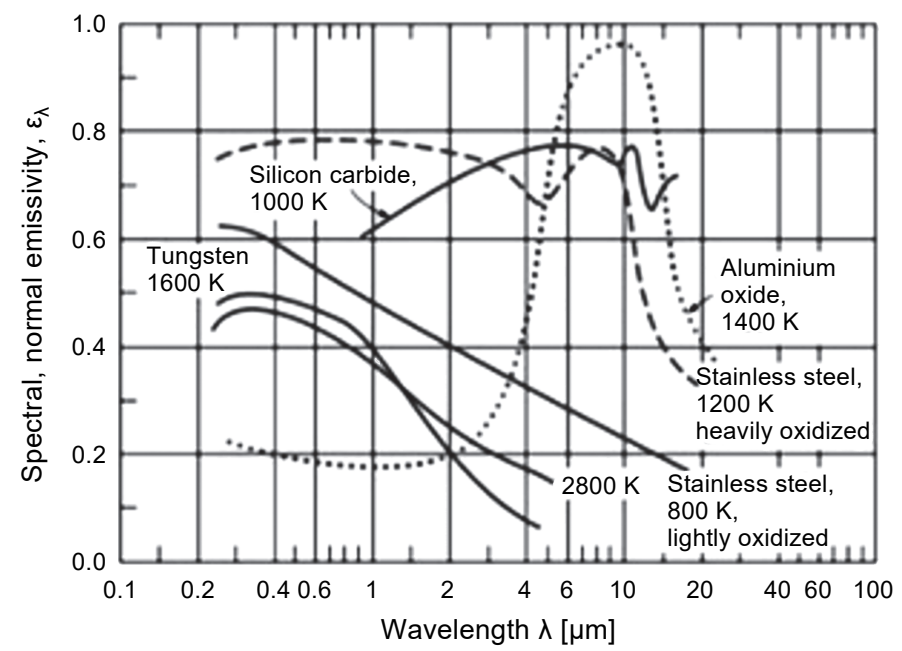

Fig. 1. Dependence of emissivity on wavelength for various materials [1]].

Another factor which influences infrared measurements results is absorption of thermal radiation by the atmosphere. During the radiation passing through the atmosphere absorption and dispersion occurs. In the red part of the optical spectrum, the absorption is mainly caused by steam, carbon dioxide, nitrogen oxide, ozone, dust and industrial fumes (Fig. 2).

The working ranges of infrared cameras are located in two atmospheric windows: 3-5 $\mu \mathrm{m}$ (SW, short wave) and 7.5-14 $\mu \mathrm{m}$ (LW, long wave) where the transmission of the infrared radiation is at the highest level.

Ordinary infrared devices need special optical components and detectors which work in the atmospheric window. These components are rather expensive and therefore the costs of non-contact thermometers are relatively high.

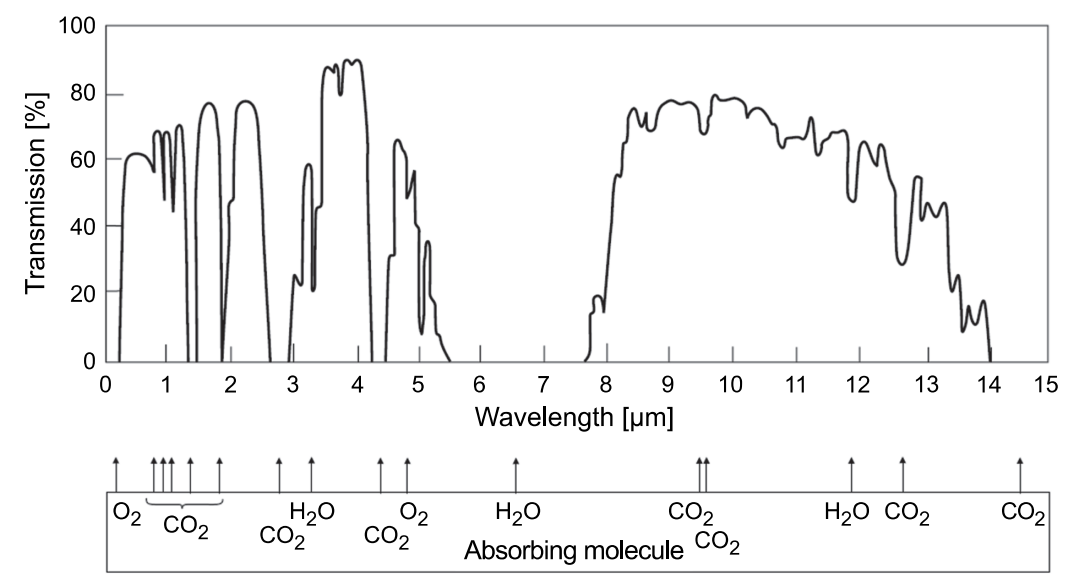

Fig. 2. Atmosphere transmission windows [2] 
The application of infrared devices in industry is limited by the conditions of the industrial process, e.g., the type of the process gases, ambient temperature and the type of the object measured. All these factors influence the changes in the signal level on the detectors and simultaneously the accuracy of the devices.

Therefore, it is crucial to seek and design new solutions, methods and devices which would allow temperature measurements to be performed remotely in a non-contact way with the elimination or limitation of the impact of emissivity and atmosphere transmission on the measurement results obtained [ $\underline{4}-\mathbf{7}]$.

\section{Laboratory verification of the temperature determination method}

Within previous pieces of work, the author's algorithm for high temperature determination was elaborated upon [ $\underline{8}, \underline{9}]$. In this paper, the laboratory verification of this method is presented.

The basis of this method is the dependence of temperature on coefficient $\alpha$ of the straight line matched to the measurement data

$$
T=\frac{2.8976 \times 10^{3}}{-0.15 \ln \left(a / 10^{6}\right)+1.35}
$$

where: $T$ - determined temperature, $\alpha$-coefficient describing the slope of the straight line. This approach does not require the emissivity value of the thermal object to be taken into account during measurements.

That method will be adopted in new thermometric devices whose construction is presented in [1]. Under laboratory conditions, preliminary tests of the optical elements of the device were carried out. The laboratory setup presented in Fig. 3 was built.
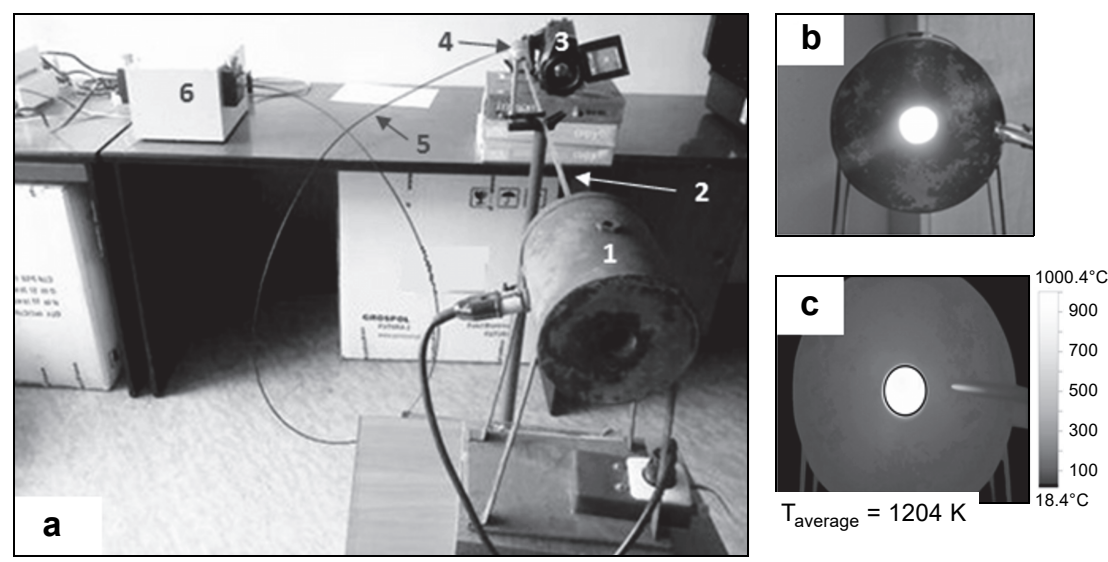

Fig. 3. Measurement setup: 1 - furnace, 2 - quartz rod, 3 - infrared camera, 4 -yellow-metal sleeve with lens, 5 - quartz fibre optic, 6 - monochromator (a), emission of the thermal radiation from the furnace (b), and thermogram of the furnace (c). 
The main element of the setup was a resistance furnace which was utilized as a thermal source whose temperature was altered. As a reference thermometer, the infrared camera was utilized.

The thermal radiation emitted by the furnace was transmitted through the quartz rod and focused on the fibre optic input and next transmitted to the detector in the monochromator. During the experiment the temperature was altered in the range from 1009 to $1423 \mathrm{~K}$ and the wavelength range from 0.625 to $0.750 \mu \mathrm{m}$. Three or four measurement series were carried out for each temperature. The number of series was dependent on the time in which the constant furnace temperature occurred.

The laboratory setup had some limitation such as setting the desirable temperature of the furnace and unequal emissions of the thermal radiation from furnace. Therefore, as a reference temperature, the mean value of the temperature shown by the infrared camera was taken.
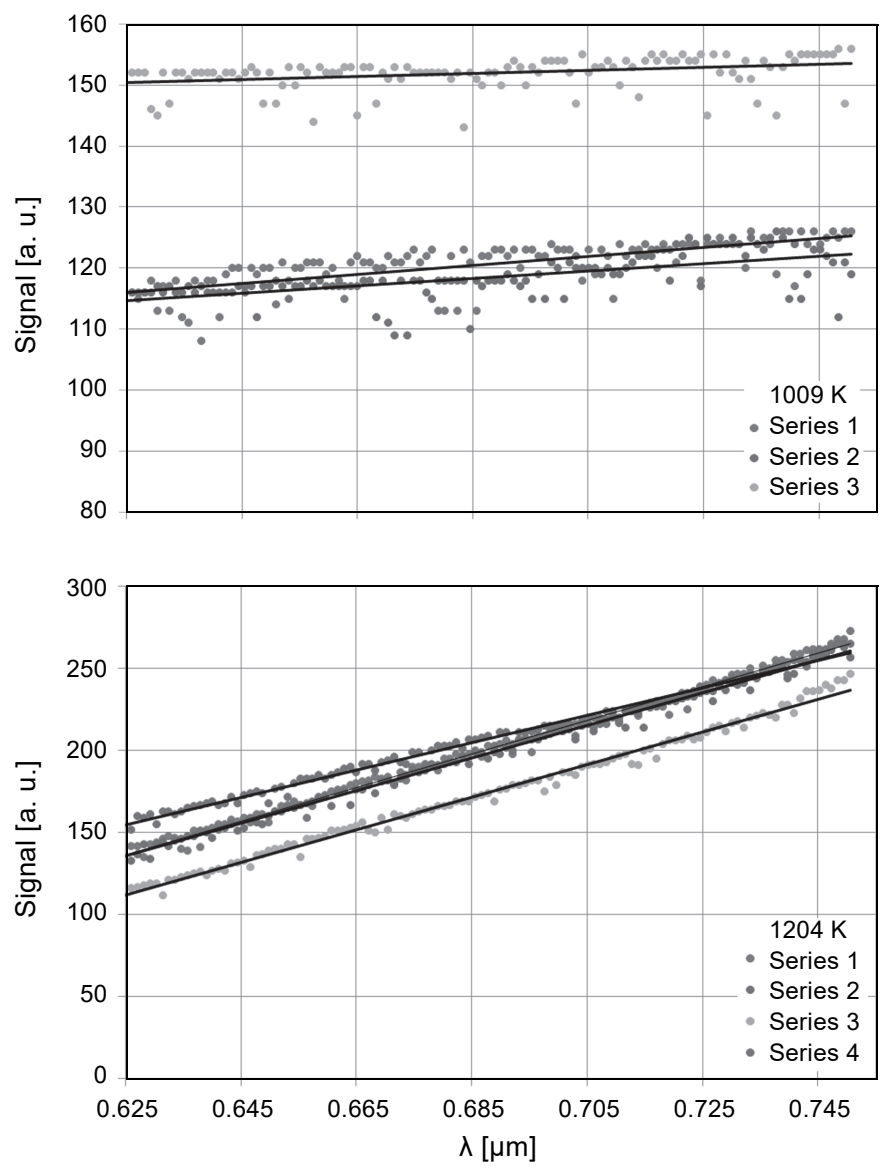

Fig. 4. Continued on the next page. 

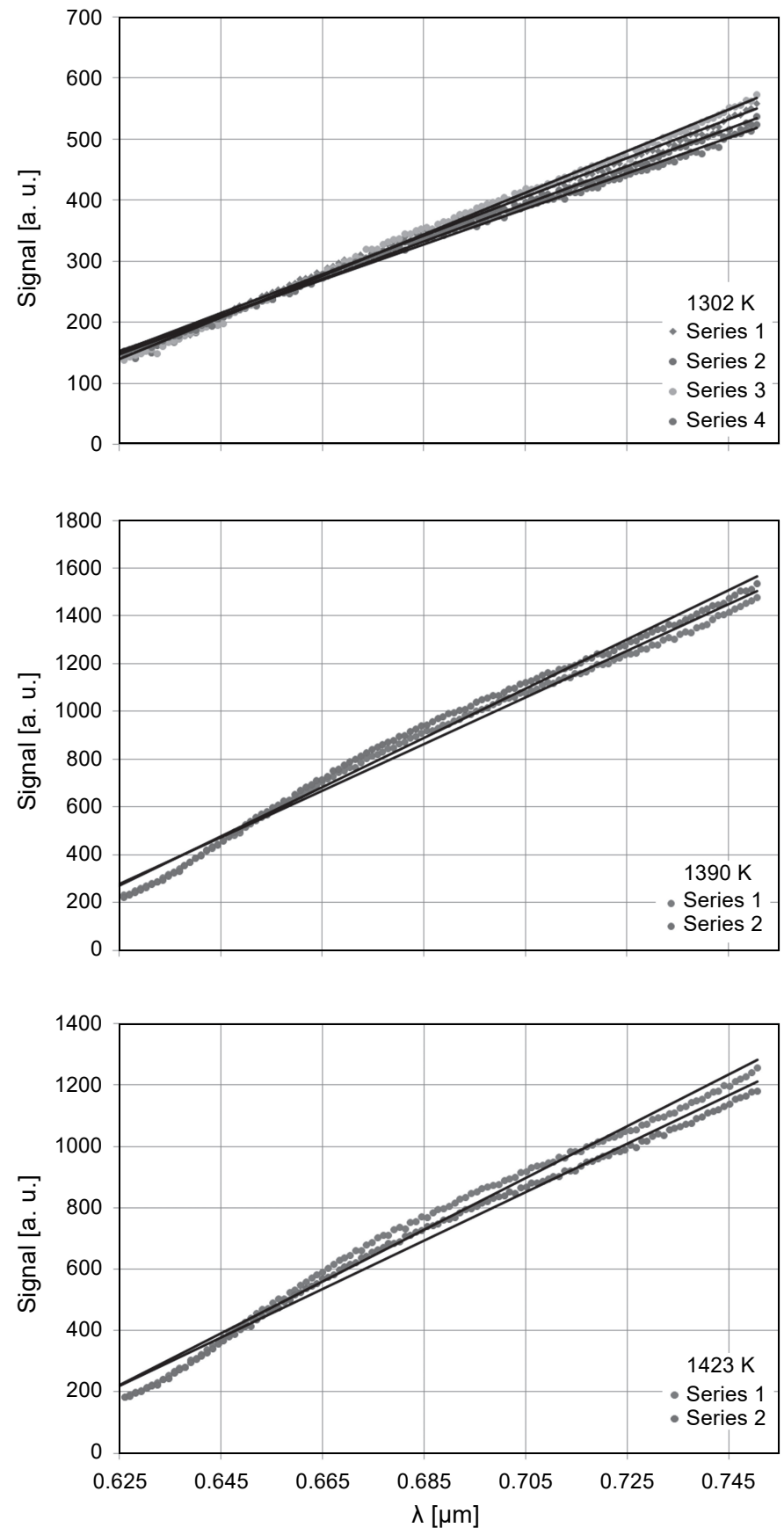

Fig. 4. The temperature measurement results for various temperatures of the furnace and straight matched lines. 
$\mathrm{T} \mathrm{a} \mathrm{b} \mathrm{l} \mathrm{e} \mathrm{1.} \mathrm{The} \mathrm{calculated} \mathrm{furnace} \mathrm{temperature} \mathrm{using} \mathrm{Eq.} \mathrm{(1).}$

\begin{tabular}{llcll}
\hline $\begin{array}{l}\text { Furnace } \\
\text { temperature }[\mathrm{K}]\end{array}$ & $\begin{array}{l}\text { Series } \\
\text { number }\end{array}$ & $\begin{array}{c}\text { Coefficient } \alpha \\
{\left[\mathrm{W} \mathrm{m}^{-2} \mu \mathrm{m}^{-2}\right]}\end{array}$ & $\begin{array}{l}\text { Calculated } T \\
{[\mathrm{~K}]}\end{array}$ & $\begin{array}{l}\text { Relative } \\
\text { error of } T[\%]\end{array}$ \\
\hline \multirow{3}{*}{1009} & 1 & 79 & 1047 & 4.0 \\
& 2 & 50 & 1022 & 1.3 \\
& 3 & 28 & 992 & 1.7 \\
\hline \multirow{3}{*}{1204} & 1 & 918 & 1208 & 0.3 \\
& 2 & 898 & 1226 & 1.8 \\
& 3 & 908 & 1207 & 2.5 \\
\hline \multirow{3}{*}{1302} & 1 & 2936 & 1302 & 0 \\
& 2 & 2863 & 1300 & 0.2 \\
\hline \multirow{2}{*}{1423} & 3 & 3149 & 1309 & 0.5 \\
& 1 & 9280 & 1412 & 1.3 \\
\hline
\end{tabular}

The results of the furnace temperature measurements for various temperatures and the straight line matched to the data are presented in Fig. 4.

In Table 1 the coefficient $\alpha$ was determined based on the linear regression of the obtained results, furnace temperatures were calculated using Eq. (1) and relative errors are presented.

The results shown in Table 1 confirm the ability of the new algorithm, based on Eq. (1), to determine the thermal source temperature without knowing the emissivity value. The maximum measurement error was $4 \%$, but it should be mentioned that the following contribute to the temperature uncertainty: the unstable temperature of the furnace and comparison of the measurement data with infrared cameras results which are dependent on emissivity value.

\section{The preliminary laboratory tests of the optical probe}

The second part of the laboratory examination involved the preliminary tests of the optical probe of new thermometric devices. According to the project described in [10], the optical device probe was constructed. The main elements of the probe were three curved rods and an optical lens. These optical elements were placed in steel housing and connected with fibre optic which transmitted the optical signal to the detector (Fig. 5).

The ability to transmit the thermal radiation through the probe was tested in the laboratory (Fig. 6).

The non-monochromatic light source was utilized as a radiation emitter and the signal of the detector was measured depending on the relative position of the probe and source. The perpendicular setting of the source and quartz rod in the optic probe was the starting position. In order to effectively connect the quartz rods with the fibre optic, 


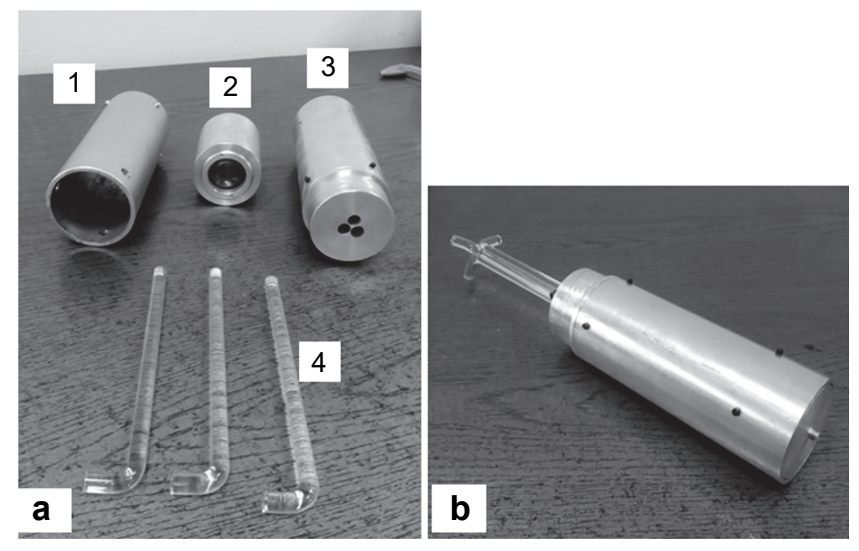

Fig. 5. The fibre optic probe; 1 - housing of the quartz rods, 2 - tube with quartz lens and fibre optic connector 3 - mounting tube of the optic elements (a), and general view (b).

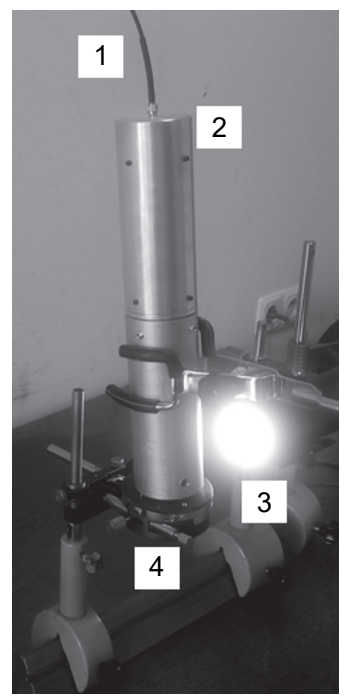

Fig. 6. The transmission measurement of the fibre optic probe: 1 - fibre optic, 2 - fibre optic probe, 3 -non-monochromatic light source, 4 -angular meter.

T a b 1 e 2. Signal on the detector related to the position of the optical elements.

\begin{tabular}{ll}
\hline Angle [deg] & Signal on the detector [\%] \\
\hline 0 & 80 \\
10 & 73 \\
20 & 68 \\
30 & 65 \\
40 & 63 \\
50 & 60 \\
60 & 57 \\
\hline
\end{tabular}


a quartz lens was used. Twenty-five meters of fibre optic was utilized to transmit the optical signal to the detector to assess the transmission losses when the measurements for long distances are conducted.

The angular ability of one rod to collect the thermal radiation ranged from $0^{\circ}$ to $60^{\circ}$ (see Table 2). For wider angles the radiation is collected partially by two rods. The registered signal is enough strong to detect the temperature changes of the thermal source. Therefore, three rods ensure the appropriate level of signal on the detector.

\section{Conclusion}

The results of the preliminary laboratory tests of the new methods of temperature determination in the non-contact thermometers were described in this paper. This method of temperature determination enables the elimination of the influence of emissivity, the attenuation of atmosphere and optical components on measurement results in devices of this kind. This algorithm utilizes the linear model of the left side of the Planck curve for different temperatures and the relationship between temperature and the straight line matched to the measurement data.

The laboratory tests confirm the strong linear dependence of measurement data in the temperature range of 1009 to $1423 \mathrm{~K}$ and for wavelengths of 0.625 to $0.75 \mu \mathrm{m}$. The new solution could change the range of wavelengths in which temperature in non-contact devices is registered.

The second part of the work involved laboratory tests of the optical probe of the non-contact device. The transmission ability of the optical component of the probe was tested. The results obtained confirm the possibility of transmitting thermal radiation emitted by the source to the detector.

The construction of the new non-contact thermometric devices based on the authors' measurement method and the utilized optical probe ensures that the fields of industrial applications of the non-contact thermometers are widened.

Acknowledgements - This research was realized as a part of statutory work No. 11110217-172 financed by Ministry of Energy.

\section{References}

[1] Cengel Y.A., Ghajar A.J., Heat and mass transfer. Fundamentals and Applications, McGraw-Hill, New York, 2011.

[2] Rogalski A., Chrzanowski K., Infrared devices and techniques, Opto-Electronics Review 10(2), 2002, pp. 111-136.

[3] Dereniak E.L., Boreman G.D., Infrared Detectors and Systems, Wiley, 1996.

[4] JONES M.R. BARKER D.G., Use of optical fiber thermometers in high temperature environments, [In] 11th IEEE International Conference on Advanced Thermal Processing of Semiconductors. RTP 2003, Charleston, SC, USA, September 23-26, 2003, DOI: 10.1109/RTP.2003.1249128.

[5] Sabel T., Unterberger S., Hein K.R.G., Application of quotient pyrometry to industrial pulverised coal combustion, Experimental Thermal and Fluid Science 26(2-4), 2002, pp. 283-289, DOI: 10.1016/S0894-1777(02)00138-3. 
[6] Char J.-M., YeH J.-H., The measurement of open propane flame temperature using infrared technique, Journal of Quantitative Spectroscopy and Radiative Transfer 56(1), 1996, pp. 133-144, DOI: 10.1016/0022-4073(96)00013-1.

[7] JiAng Z.-W., Luo Z.-X., Zhou H.-C., A simple measurement method of temperature and emissivity of coal-fired flames from visible radiation image and its application in a CFB boiler furnace, Fuel 88(6), 2009, pp. 980-987, DOI: 10.1016/j.fuel.2008.12.014.

[8] Lisiecka E., Passia H., Koncepcja metody i urzadzenia do optycznego pomiaru wysokich temperatur, Pomiary Automatyka Kontrola 60(5), 2014, pp. 272-274 (in Polish).

[9] LISIECKA E., Reduction of the impact of emissivity on high temperature measurements in non-contact thermometric devices, Optica Applicata 47(3), 2017, pp. 373-381, DOI: 10.5277/oa170304.

[10] Passia H., Lisiecka E., Stańczyk K., Fibre-optic probe for measuring high temperatures in the underground coal gasification reactor, enabled by vertical holes from the surface, UPRP Pat.225056.

Received June 25, 2018

in revised form September 22, 2018 